AUdiology

\title{
Psychometric properties of the Italian Tinnitus Functional Index (TFI)
}

\author{
Proprietà psicometriche della versione italiana del Tinnitus Functional Index (TFI) \\ Stefania Barozzi1,2, Luca Del Bo², Silvia Passoni², Daniela Ginocchio³, Luca Negri², Andrea Crocetti², \\ Umberto Ambrosetti ${ }^{1,3}$ \\ ${ }^{1}$ Audiology Unit, Department of Clinical Sciences and Community Health, University of Milan, Italy; ${ }^{2}$ Fondazione Ascolta e Vivi, \\ Milan, Italy; ${ }^{3}$ UOSD Audiology, Fondazione IRCCS Cà Granda, Ospedale Maggiore Policlinico, Milan, Italy
}

\begin{abstract}
SUMMARY
Various questionnaires are used to assess the impact of tinnitus on the quality of life. The Tinnitus Functional Index (TFI) has excellent properties for scaling the severity of tinnitus and treatment-related changes in both clinical and research settings. The aim of this study was to evaluate the psychometric properties of the Italian version of the TFI with particular emphasis on factor analysis, internal consistency, reliability and validity. The original English version of the TFI was translated into Italian using the translation/back - translation process; 137 participants who were recruited at the Tinnitus Clinic in Milan and had suffered from tinnitus for at least three months (39.4\% females, age: 18-80 years, mean age: 48.26, SD: 14.08) completed the Italian version of the TFI, the Tinnitus Handicap Inventory (THI), the Beck Depression Inventory - Primary Care Version (BDI-PC) and the Numeric Rating Scale of annoyance (NRS-A). Of these patients, 57 completed the TFI again at a second visit 7-14 days later, before undergoing any intervention, in order to provide data for reproducibility assessment. The psychometric properties were investigated using exploratory factor analysis and internal consistency and test-retest reliability instruments. The convergent validity of the TFI was evaluated using correlation coefficients obtained from the remaining measurements. The Italian TFI has a four-factor structure that was somewhat different from the original. The internal consistency proved to be good $(0.92 \leq \alpha \leq 0.96)$ as did the test-retest reliability $(0.79 \leq \alpha \leq 0.85)$. In terms of convergent validity, the TFI showed high correlations with the THI $(r=0.77)$ and the NRS-A $(r=0.70)$ scores, and moderate correlations with the BDI-PC scores $(r=0.46)$. The difficulties encountered when attempting to reproduce the original eight-factor structure were consistent with other studies in which the TFI was translated into European languages. In spite of this, the factorial structure of the Italian version of the TFI was characterised by high levels of reliability and validity. Overall, the Italian adaptation of the TFI was shown to be suitable to measure the impact of tinnitus on the daily lives of individuals.
\end{abstract}

KEY WORDS: tinnitus, exploratory factor analysis, convergent validity, reliability, outcome instruments

\section{RIASSUNTO}

Diversi questionari sono utilizzati per valutare l'impatto dell'acufene sulla qualità della vita. Il Tinnitus Functional Index (TFI) proposto da Meikle et al, nel 2012, ha dimostrato proprietà eccellenti per misurare la gravità e le modificazioni indotte dal trattamento degli acufeni, sia in ambito clinico che di ricerca. Lo scopo di questo studio è stato valutare le proprietà psicometriche della versione italiana del TFI, in particolare, l'analisi fattoriale, la consistenza interna, l'affidabilità e la validità. La versione originale inglese del TFI ̀̀ stata tradotta in italiano secondo la procedura translation - back translation; 137 partecipanti con acufeni da almeno 3 mesi (39,4\% femmine, età: 18-80 anni, età media: 48,26, SD: 14,08), reclutati presso la Tinnitus Clinic di Milano, hanno completato la versione italiana del TFI, il Tinnitus Handicap Inventory, la Beck Depression Inventory - Versione Primary Care e la scala di valutazione numerica per il fastidio. Una parte del campione, 57 pazienti, ha completato la versione italiana del TFI in una seconda visita, dopo 7-14 giorni, prima di ricevere qualsiasi tipo di trattamento, per ricavare i dati per la valutazione della
Received: November 17, 2018

Accepted: April 13, 2019

Correspondence

Stefania Barozzi

Audiology Unit, Department of Clinical Sciences and Community Health, University of Milan, via F. Sforza 35, 20122 Milan, Italy

Tel. +390255033922

E-mail: stefania.barozzi@gmail.com

Funding

None.

Conflict of interest

The Authors declare no conflict of interest.

How to cite this article: Barozzi S, Del Bo L, Passoni S, et al. Psychometric properties of the Italian Tinnitus Functional Index (TFI). Acta Otorhinolaryngol Ital 2020;40:230-237. https:// doi.org/10.14639/0392-100X-2432

(c) Società Italiana di Otorinolaringoiatria e Chirurgia Cervico-Facciale

\section{cc) $\$$}

This is an open access article distributed in accordance with the CC-BY-NC-ND (Creative Commons Attribution-NonCommercial-NoDerivatives 4.0 International) license. The article can be used by giving appropriate credit and mentioning the license, but only for non-commercial purposes and only in the original version. For further information: https:// creativecommons.org/licenses/by-nc-nd/4.0/deed.en 
riproducibilità. Le proprietà psicometriche sono state studiate attraverso un'analisi fattoriale esplorativa ed il calcolo di misure di consistenza interna e affidabilità test-retest. La validità convergente è stata valutata mediante i coefficienti di correlazione con le restanti misure. La versione italiana del TFI ha mostrato una struttura a quattro fattori, parzialmente diversa dalla struttura originale a otto fattori. L'adattamento italiano del TFI ha rivelato buoni livelli di consistenza interna $(0,92 \leq \alpha \leq 0,96)$ e affidabilità test-retest $(0,79 \leq \alpha \leq 0,85)$. In termini di validità convergente, ha mostrato buone correlazioni con i punteggi del THI $(r=0,77)$ e della scala del fastidio $(r=0,70) e$ correlazioni medie con i punteggi del BDI $(r=0,46)$. Le difficoltà nel riprodurre la struttura originale a otto fattori sono coerenti con altri studi di validazione del TFI nelle lingue europee. Nonostante tali discrepanze, la versione italiana del TFI ha mostrato una struttura fattoriale caratterizzata da alti livelli di affidabilità e validità. Nel complesso, l'adattamento italiano di TFI si è rivelato idoneo a misurare l'impatto degli acufeni sulla vita quotidiana degli individui.

PAROLE CHIAVE: acufene, analisi fattoriale esplorativa, validità convergente, affidabilità

\section{Introduction}

Tinnitus is generally defined as the perception of sound in the absence of a corresponding external stimulus. It is a common auditory complaint with prevalence rates ranging from $2.4 \%$ to $20.1 \%{ }^{1}$. Some people can ignore this phantom sound, while others suffer considerably and consequently, with negative impact on the quality of life. Tinnitus is a purely subjective phenomenon and lacks any objectively identifiable markers; moreover, tinnitus may affect different domains of well-being (i.e. sleep, concentration, hearing, emotions). For these reasons, quantifying the severity of this symptom and how it changes over time and with treatment is challenging.

Several questionnaires have now been developed and validated for assessment of tinnitus complaints: Tinnitus Handicap Questionnaire 2, Tinnitus Reaction Questionnaire ${ }^{3}$, Tinnitus Handicap Inventory (THI) ${ }^{4}$, Tinnitus Questionnaire (TQ) ${ }^{5}$ and its short form, Mini-TQ ${ }^{6}$ and the Tinnitus Primary Function Questionnaire ${ }^{7}$. The THI and Mini-TQ have also been validated in their Italian language versions ${ }^{8,9}$. More recently Moschen et al. validated the Italian version of the Chronic Tinnitus Acceptance Questionnaire (CTAQ-I) ${ }^{10}$.

In 2012, Meickle et al. proposed the Tinnitus Functional Index (TFI) ${ }^{11}$. The TFI has been shown to be a sensitive tool to rate the severity and negative impact of tinnitus and is especially effective in evaluating the effects of treatment. Since its publication, the TFI has received considerable international attention in both clinical and research settings and has become the new "gold standard". It has been translated into and validated in a number of languages including Dutch ${ }^{12}$, Polish ${ }^{13}$, Swedish ${ }^{14}$, German ${ }^{15,16}$, Hebrew ${ }^{17}$ and Chinese ${ }^{18,19}$. To our knowledge, there has been no validated Italian version to date.

The TFI consists of 25 items, each rated on a 11-point Likert scale. Patients rate each item according to how they have felt over the past week. The total score varies from 0 to 100 and is classified according to five levels of clinical severity ${ }^{20}$ : not a problem (0-17); small problem (18-31); moderate problem (32-53); big problem (54-72); very big problem (73-100). The TFI incorporates eight subscales named: Intrusive (items 1-3), Sense of Control (items 4-6), Cognitive (items 7-9), Sleep (items 10-12), Auditory (items 13-15), Relaxation (items 16-18), Quality of Life (items 19-22) and Emotional (items 23-25). In addition to the total score, the subscale scores can be calculated. A reduction of 13 in the TFI score is considered a significant reduction in discomfort ${ }^{20}$.

The aim of this study was to evaluate the psychometric properties of the Italian TFI (I-TFI). More specifically, we investigated the factor structure of the instrument together with its internal consistency, test-retest reliability, convergent and discriminant validity.

\section{Materials and methods}

\section{Procedures}

The study was carried out in accordance with the Declaration of Helsinki. For this trial, participants were recruited at the Tinnitus Clinic in Milan where they had referred a complaint of tinnitus. Patients were included in this study if they had had tinnitus for a minimum of three months, were fluent in the Italian language, were at least 18 years old and had normally cognitive function and preserved reading skills. All of the subjects enrolled in the study gave written informed consent. None of the patients was undergoing any type of treatment for tinnitus at the time of evaluation.

During their first examination at the Tinnitus Clinic (T0), all participants underwent complete audiological evaluation including full medical anamnesis, otomicroscopy and pure-tone audiometry in a sound attenuated room. Hearing levels were measured in each ear separately at $0.25-8 \mathrm{kHz}$ at half octave steps for air conduction and at $0.5-4 \mathrm{kHz}$ for bone conduction. The Pure Tone Average (PTA) was measured at $0.5,1$ and $2 \mathrm{kHz}$. After audiological assessment, the participants completed the I-TFI, THI, Beck Depression Inventory - Primary Care Version (BDI-PC) ${ }^{21}$ and a Numeric Rating Scale of annoyance (NRS-A). Of the patients who took part in the first survey, a group was selected for test- 
retest reliability analysis. For this purpose, these patients were asked to complete the I-TFI a second time within a 1-2-week interval (T1) and before undergoing any intervention, in order to provide data for reproducibility assessment. A variation of two days before or after the requested one/two-week long interval between trials was considered acceptable in compliance with the patients' needs. No access to the responses given in the first questionnaire was allowed to patients when filling out the second I-TFI. All of the participants included in the study completed the I-TFI without assistance. The time required to fill out the questionnaire was approximately 10 minutes.

The study consisted of two different phases: a translation and cross-cultural adaptation process (phase 1) and analysis of psychometric properties (phase 2).

\section{Participants}

One hundred and fifty subjects (40\% females) attending the Tinnitus Clinic of Milan were asked to participate in this study; 13 patients refused to participate and therefore 137 adults aged $18-80$ years $\left(39.4 \%\right.$ females $\mathrm{M}_{\text {age }}=48.26$, $\left.\mathrm{SD}_{\text {age }}=14.08\right)$ suffering from tinnitus were included. All were examined by an ENT physician, underwent the audiometric tests described above and completed the I-TFI, I-THI, BDI-PC and NRS-A. Of the 137 patients who took part in the first survey, 70 were selected for the second survey based on the I-TFI questionnaire alone. 57 participants completed the second questionnaire within the accepted period and their scores were therefore included in the testretest reliability analysis (10 patients did not complete the I-TFI within the accepted period of time and three did not complete the second questionnaire).

\section{Measures}

1. The TFI ${ }^{11}$ consists of 25 items: the patient answers each question by giving a score ranging from 0 to 10 (except for items 1 and 3, which are expressed as a percentage ranging from $0 \%$ to $100 \%$ ). The overall TFI score is calculated by multiplying the mean of all questions by 10 (questions 1 and 3 must be converted into a $0-10$ scale) or dividing the sum of all of the scores by 2.5 , to give a global score out of 100 . Subscales are calculated as the mean of the answered questions multiplied by 10 .

2. The THI ${ }^{4}$ is one of the most commonly used questionnaires for assessing tinnitus distress and reporting treatment outcomes. The THI consists of 25 items that can be divided into three subscales: Functional, Emotional and Catastrophic. Patients score their symptoms on a three-point scale. The total score ranges from 0 to 100 ; a higher score is indicative of greater tinnitus distress.
Good reliability (0.94) and validity were reported for the total score of the Italian $\mathrm{THI}^{8,22}$.

3. The BDI-PC ${ }^{21}$ is a screening instrument for depression that minimises the possibility of yielding spuriously high estimates of depression for patients with medical problems by focusing on symptoms of sadness, pessimism, past failure, loss of pleasure, self-dislike, selfcriticalness and suicidal thoughts or wishes. Its seven items are taken from the Beck Depression InventoryII $^{23}$. Each item is rated on a 4-point scale ranging from 0 to 3 , and the BDI-PC score is calculated by summing up all of the highest ratings for each of its seven items. The respondents are asked to describe their feelings "over the past 2 weeks, including today."

4. NRS-A: the patient is asked to rate tinnitus-related annoyance from 0 (minimal annoyance) to 10 (maximum annoyance). Of the 137 participants, only 125 answered this scale at $\mathrm{T} 0$.

\section{Translation and cultural adaptation process (phase 1)}

A cross-cultural adaptation process of translation and backtranslation was followed in accordance with the "Principles of Good Practice for the Translation and Cultural Adaptation Process for Patient-Reported Outcome Measures" ${ }^{24}$. Two professional translators carried out independent forward translations of the original TFI into Italian (forward translation). Discussion of the translated manuscripts with an otorhinolaryngologist and an audiologist with extensive experience in tinnitus resolved discrepancies between the original independent translations and ensured a single forward translation (reconciliation). This new and final version of the I-TFI was then translated back into English by a qualified professional translator (backward translation). The same professional translator compared this back-translation to the original manuscript; no signs of incongruent translation were noted as every item was semantically identical to the original English manuscript (back translation review). The final I-TFI was tested for cognitive equivalence by a group of tinnitus patients who discussed the wording and the meaning of each item of the I-TFI with the clinicians. Subsequently, the wording of the questionnaire was modified on the basis of the suggestions given by patients (cognitive debriefing and finalisation).

\section{Analysis of psychometric properties (phase 2)}

\section{CONSTRUCT VALIDITY}

An exploratory factor analysis was carried out to investigate the I-TFI structure with the aim of replicating the questionnaire's original eight-factor configuration.

The final number of factors to be retained was identified by two selection methods: Kaiser-Guttman criterion ${ }^{25}$ and 
Cattell's Scree test; as a consequence, only factors with eigenvalues greater than one or positioned to the left of the inflexion point on the eigenvalue plot were inspected further. Parallel analysis was also carried out in order to corroborate the identified factor solution.

Since Mardia's multivariate omnibus test showed violation of the assumption of multivariate normality, a Principal Axis Factoring (PAF) analysis was carried out ${ }^{26}$. The direct oblimin rotation method made it possible to correlate the factors.

\section{INTERNAL CONSISTENCY AND TEST-RETEST RELIABILITY}

Internal consistency and test-retest reliability were investigated using inspection of Cronbach's alphas and test-retest $\alpha$ coefficients respectively. In line with literature, values between 0.70 and 0.79 were considered acceptable, scores between 0.80 and 0.89 good, and values higher than 0.90 were deemed excellent.

\section{CONVERGENT AND DISCRIMINANT VALIDITY}

As a final step, the instrument's convergent and discriminant validity were investigated using Pearson bivariate correlation coefficients. In order to evaluate convergent validity, the I-TFI total and subscale scores were correlated with the global scores from the THI and the NRS-A scale. Similarly, in order to evaluate discriminant validity, the total and subscale scores of the I-TFI were correlated with the global BDI-PC score. In line with literature, values below $10.30 \mid$ were interpreted as indices of absence of meaningful association between the involved constructs; values between $|0.30|$ and $|0.49|$ were deemed as indices of low correlation, values between $|0.50|$ and $10.69 \mid$ as indices of moderate correlation and values above $10.70 \mathrm{l}$ as indices of high correlation between constructs ${ }^{27}$.

\section{Results}

A total of 54 females and 83 males completed the I-TFI questionnaire at $\mathrm{T} 0$. The mean PTA for the right ear was $16.35 \mathrm{~dB}$ HL (SD: 12.45) and for the left ear 18.23 dB HL (SD: 13.34). Descriptive statistics for all of the I-TFI items at T0 were subsequently calculated (Tab. I). No univariate outlier emerged in item distribution, although the results of Mardia's multivariate omnibus test indicated a violation of the assumption of multivariate normality. For this reason, exploratory factor analysis (EFA) with Principal Axis Factoring rather than Principal Component Analysis was preferred.

\section{Factor analysis}

All of the I-TFI items were initially checked to make sure that the EFA assumptions were met. Sampling adequa-
Table I. Descriptive statistics of the I-TFI.

\begin{tabular}{lccccc} 
Item & Min-Max & $\mathbf{M}(\mathrm{SD})$ & Item & Min-Max & $\mathbf{M}(\mathrm{SD})$ \\
\hline 1. & $1-10^{\star}$ & $6.42(2.82)$ & 14. & $1-10$ & $2.51(2.95)$ \\
2. & $1-10$ & $5.88(2.20)$ & 15. & $1-10$ & $2.69(3.13)$ \\
3. & $1-10^{\star}$ & $5.56(3.06)$ & 16. & $1-10$ & $3.79(3.43)$ \\
4. & $1-10$ & $6.68(3.18)$ & 17. & $1-10$ & $4.62(3.15)$ \\
5. & $1-10$ & $6.38(2.93)$ & 18. & $1-10$ & $5.45(3.38)$ \\
6. & $1-10$ & $6.34(2.83)$ & 19. & $1-10$ & $3.30(3.24)$ \\
7. & $1-10$ & $4.15(3.06)$ & 20. & $1-10$ & $3.64(3.58)$ \\
8. & $1-10$ & $3.66(3.21)$ & 21. & $1-10$ & $3.28(3.25)$ \\
9. & $1-10$ & $3.72(2.94)$ & 22. & $1-10$ & $3.35(3.18)$ \\
10. & $1-10$ & $4.23(3.52)$ & 23. & $1-10$ & $4.69(3.39)$ \\
11. & $1-10$ & $3.72(3.45)$ & 24. & $1-10$ & $5.69(3.12)$ \\
12. & $1-10$ & $3.73(3.57)$ & 25. & $1-10$ & $3.93(3.44)$ \\
13. & $1-10$ & $2.80(3.02)$ & & & \\
\hline
\end{tabular}

N: number of participants; M: mean; SD: standard deviation; ${ }^{\star} 1-100 \%$ scores converted to $1-10$.

cy was verified using the Kaiser-Meyer-Olkin measure (KMO). The total KMO value was 0.92 and all of the KMO values for the individual items were higher than 0.77 , and therefore above the threshold value of $0.60{ }^{28}$. Bartlett's test of sphericity $\left(c^{2}(300=4060.38 \mathrm{p}<0.001)\right.$ indicated that between-item correlations were sufficiently large to perform EFA.

Both Kaiser-Guttman's criterion and Scree plot inspection suggested a four-factor solution, together explaining $75.8 \%$ of the variance. The four-factor solution also showed eigenvalues higher than the cut-off value suggested by Parallel Analysis ${ }^{29}$. These results show that the I-TFI factor structure differs from the original eight-factor solution observed by Meikle et al. ${ }^{11}$.

Table II shows the I-TFI factor loading matrix.

Overall, all items showed primary loadings higher than 0.60 on one of the four factors, with the exception of items 18 (0.43), 21 (0.57), and 24 (0.42); at the same time, items 18 and 24 were the only items, (together with item 17) that had cross-loading values higher than 0.30 with a second factor.

As Table II shows, the first extracted factor of the I-TFI (Factor 1) combined items from the Intrusive (I) and Sense of Control (S) subscales of the original instrument's structure, together with item 24 whose primary loading in the eight-factor structure was on the Emotional subscale (E). With the exclusion of item 24, our results showed that items belonging to the Cognitive (C), Quality of life (Q) and Emotional (E) factors of the original structure collapsed into the second I-TFI factor (Factor 2). Auditory (A) was the only factor that completely mirrored the solution proposed by Meikle et al. ${ }^{20}$. Finally, the fourth I-TFI fac- 
Table II. Exploratory factor analysis (principal axis factoring): oblimin-rotated factor loadings.

\begin{tabular}{|c|c|c|c|c|}
\hline Item & $\begin{array}{l}\text { Factor } 1 \\
\text { (I)ntrusive/ } \\
\text { (S)ense } \\
\text { of Control/ } \\
\text { (item 24) }\end{array}$ & $\begin{array}{l}\text { Factor } 2 \\
\text { (C)ognitive/ } \\
\text { (Q)uality } \\
\text { of life/ } \\
\text { (E)motional }\end{array}$ & $\begin{array}{l}\text { Factor } 3 \\
\text { (A)uditory }\end{array}$ & $\begin{array}{c}\text { Factor } 4 \\
\text { (SL)eep/ } \\
\text { (R)elaxation }\end{array}$ \\
\hline $1(I)$ & 0.71 & & & \\
\hline $2(I)$ & 0.78 & & & \\
\hline $3(I)$ & 0.77 & & & \\
\hline $4(S)$ & 0.78 & & & \\
\hline $5(S)$ & 0.75 & & & \\
\hline $6(S)$ & 0.78 & & & \\
\hline $7(C)$ & & 0.90 & & \\
\hline $8(C)$ & & 0.96 & & \\
\hline $9(\mathrm{C})$ & & 0.83 & & \\
\hline 10 (SL) & & & & 0.87 \\
\hline 11 (SL) & & & & 0.96 \\
\hline $12(\mathrm{SL})$ & & & & 0.92 \\
\hline $13(A)$ & & & 0.84 & \\
\hline $14(\mathrm{~A})$ & & & 0.98 & \\
\hline $15(\mathrm{~A})$ & & & 0.91 & \\
\hline $16(\mathrm{R})$ & & & & 0.93 \\
\hline $17(\mathrm{R})$ & & 0.32 & & 0.51 \\
\hline $18(\mathrm{R})$ & 0.35 & & & 0.43 \\
\hline $19(Q)$ & & 0.64 & & \\
\hline $20(Q)$ & & 0.66 & & \\
\hline $21(Q)$ & & 0.57 & & \\
\hline $22(\mathrm{Q})$ & & 0.68 & & \\
\hline $23(\mathrm{E})$ & & 0.64 & & \\
\hline $24(\mathrm{E})$ & 0.42 & 0.37 & & \\
\hline $25(\mathrm{E})$ & & 0.79 & & \\
\hline
\end{tabular}

N: number of participants; Bold: item highest factor loading; loadings below 30 are not reported; (I): Intrusive; (S): Sense of control; (C): Cognitive; (SL): Sleep; (A): Auditory; (R): Relaxation; (Q): Quality of Life; (E): Emotional.

tor (Factor 4) combined the Sleep (SL) and Relaxation (R) items from the original factor structure.

As for the level of association among the four I-TFI factors, Table III shows the correlation values together with descriptive statistics.

In general, negligible or low correlations were found among factors, with the exception of factor 2 which showed moderate levels of association with both factor 1 and factor 4 .

As a last step, an additional EFA with a fixed eight-factor structure was performed in order to test the original structure suggested by Meickle and colleagues. All of the items showed primary loadings on the expected items with the exception of item 16 that loaded on the Sleep factor (data are available from the corresponding author upon request).
Table III. I-TFI factor correlation and descriptive statistics.

\begin{tabular}{lcccc}
$\mathbf{N}=137$ & $\mathbf{1 .}$ & $\mathbf{2 .}$ & $\mathbf{3 .}$ & $\mathbf{4 .}$ \\
$\begin{array}{l}\text { 1. (I)ntrusive/(S)ense } \\
\text { of Control/(item 24) }\end{array}$ & - & & & \\
2. (C)ognitive/(Q)uality of & 0.54 & - & & \\
$\begin{array}{l}\text { Life/(E)motional } \\
\text { 3. (A)uditory }\end{array}$ & & & & \\
4. (SL)eep/(R)elaxation & 0.45 & 0.39 & - & - \\
Min-Max & $6-70$ & 0.61 & 0.14 & -80 \\
M & 42.95 & 33.71 & 8 & 25.52 \\
SD & 16.47 & 25.21 & 8.75 & 18.58 \\
\hline M: Mean; SD: Standard Deviation; (I): Intrusive; (S): Sense of control; (C): Cognition; \\
(SL): Sleep; (A): Auditory; (R): Relaxation; (Q): Quality of Life; (E): Emotional.
\end{tabular}

Table IV. Internal consistency and test-retest reliability.

\begin{tabular}{|c|c|c|c|}
\hline & $\begin{array}{c}\alpha \mathrm{T0} \\
(\mathrm{N}=137)\end{array}$ & $\begin{array}{c}\alpha \mathrm{T} 1 \\
(\mathrm{~N}=57)\end{array}$ & $\begin{array}{l}\alpha(\mathrm{T} 0-\mathrm{T} 1) \\
(\mathrm{N}=57)\end{array}$ \\
\hline $\begin{array}{l}\text { 1. (I)ntrusive/(S)ense } \\
\text { of Control/(item 24) }\end{array}$ & 0.91 & 0.91 & 0.79 \\
\hline $\begin{array}{l}\text { 2. (C)ognitive/(Q)uality of } \\
\text { Life/(E)motional }\end{array}$ & 0.96 & 0.95 & 0.81 \\
\hline 3. (A)uditory & 0.96 & 0.97 & 0.85 \\
\hline 4. (SL)eep/(R)elaxation & 0.96 & 0.94 & 0.84 \\
\hline I-TFI total score & 0.96 & 0.95 & 0.83 \\
\hline
\end{tabular}

\section{Internal consistency and test-retest reliability}

Internal consistency was evaluated using Cronbach's alpha indices calculated for each of the four factors and for the total I-TFI score at T0 $(\mathrm{N}=137)$ and $\mathrm{T} 1(\mathrm{~N}=57)$; the testretest alpha coefficient ${ }^{30}$ was employed to evaluate testretest reliability ( $\mathrm{T} 0-\mathrm{T} 1, \mathrm{~N}=57$ ).

The results are reported in Table IV. All of the Cronbach $\alpha$ indices showed very high levels of internal consistency $(>0.90)$. As for test-retest reliability, it ranged from 0.79 (Factor 1), to 0.85 (Factor 3 ) indicating acceptable to good levels of reliability.

\section{Convergent and discriminant validity of the I-TFI}

Both the convergent and discriminant validity of the instrument were assessed at T0 using Pearson's correlation coefficients calculated between the total I-TFI score and: a) the THI; b) the BDI-PC, c) the NRS-A. The descriptive statistics and correlation matrix of all of the instruments employed are reported in Table V.

The total I-TFI score showed a high positive correlation with both the THI and the NRS-A, demonstrating acceptable levels of convergent validity with measures related to 
Table V. I-TFI convergent and discriminant validity: Pearson's correlation indices and descriptive statistics.

\begin{tabular}{lcccc} 
& $\mathbf{1 .}$ & $\mathbf{2 .}$ & $\mathbf{3 .}$ & $\mathbf{4 .}$ \\
TFI (total score) & - & & & \\
THI & $\mathbf{0 . 7 7 ^ { * * }}$ & - & & \\
NRS-A & $\mathbf{0 . 7 0 ^ { * * }}$ & $0.64^{\star \star}$ & - & \\
BDI-PC & $\underline{0.46^{\star \star}}$ & $0.63^{\star \star}$ & $0.43^{\star \star a}$ & - \\
Min-Max & $3-95$ & $0-94$ & $0-10 \mathrm{a}$ & $0-17$ \\
M & 44.08 & 37.64 & $5.92 \mathrm{a}$ & 2.31 \\
SD & 23 & 21.75 & $2.09 \mathrm{a}$ & 2.98 \\
\hline
\end{tabular}

M: Mean; SD: Standard deviation; Bold: Convergent validity; Underlined: Discriminant validity; ${ }^{* *} p<0.01 ;{ }^{a} \mathrm{~N}: 125$

tinnitus construct. Moreover, acceptable levels of discriminant validity are suggested by the low association between the total I-TFI score and that of the BDI-PC. Even though both depression and tinnitus can be considered weakly related, as both are an expression of the health-illness continua, each dimension is characterised by distinctive features.

\section{Discussion}

This is the first study aimed at examining the psychometric properties (i.e. the factor structure, internal consistency and test-retest reliability, and validity) of the Italian TFI in a clinical sample of Italian adults experiencing tinnitus. It is important to carry out thorough evaluation of the psychometric properties of a questionnaire in order to assess whether this instrument is a reliable and valid form of measurement.

Unlike the original structure, analysis of the I-TFI demonstrates that the best factorial structure is four factors. Factor 1 includes items that originally loaded on Intrusiveness (1-3) and Sense of Control (4-6), and item 24 ("how bothered or upset have you been...") which originally loaded on Emotional distress. Factor 2 comprises the original Cognitive (7-9), Quality of Life (19-22) and Emotional $(23,25)$ items. Factor 3 includes the three Auditory items (13-15). Factor 4 contains the Sleep (10-12) and Relaxation items (16-18).

Similarly, the evaluations of TFI versions translated into other languages show some uncertainty regarding its factor structure: using the eigenvalues $>1$ criterion, the Dutch version found 7 factors, the Swedish 6 factors and the Polish version identified 5 factors; the German TFI extracted 5 factors adopting the less restrictive Jolliffe's criterion (eigenvalues $>0.7$ ).

Similar to the German validation, our study groups the original Intrusive and Sense of Control items in Factor 1, but with the addition of item 24 (Intrusive/Sense of Con- trol/item 24). A possible explanation of the attribution of item 24 to the same factor loading Intrusiveness and Sense of Control items could be the Italian translation: in fact, the Italian translation for "bothered" (item 24) is similar (but not the same) as "annoyed" (item 3). Furthermore, in our study item 24 showed comparable loadings with factor 2 , which included Emotional items.

Factor 2 of our extracted factors included three subscales of the original TFI: Cognitive, Quality of Life and Emotional. This result is supported by a similar finding during the validation of the German version for Switzerland; the Dutch version also combined the two subscales, Cognitive and Quality of Life, in one factor. This result can be justified by examining the content of the items involved in the Emotional and Cognitive scales. The former presents the topics of activation (two items) and depressed mood (one item), while the latter includes items concerning attention capacity. A link could be hypothesised if we were to consider the influence of hyperactivation on attention skills. The item concerning mood in the Emotional scale, together with items about activation, could have some concept points in common with the scale of Quality of Life, where items are about the pleasure of being involved in social activities or other commitments, linking anxiety and depressive moods with a decreased hedonia.

Factor 3 is the only factor to be defined individually and corresponds to the Auditory subscale of the questionnaire; moreover, it has high factor loadings $(0.84,0.98,0.91)$. Validations in other languages, even those that did not confirm the eight-factor structure, also found the Auditory factor to be separate. Recently, Fackrell et al. suggested that the Auditory subscale does not contribute to the level of global functional impact of tinnitus and proposed a modified seven-factor model, without the Auditory items, which fits the variance in the patients' scores better ${ }^{31}$.

Factor 4 incorporates the Sleep and Relaxation items. Herein, features of tinnitus often disturb the falling asleep phase, during which the transition from the vigil state of consciousness to the state of sleep requires relaxing parasympathetic processes.

An EFA with the superimposed eight-factor structure was also performed to investigate whether the original structure suggested by Meickle et al. could be confirmed. In this case, primary loadings of the items loaded on the original factors with the exception of item 16 that loaded on Sleep. Furthermore, the definition "quiet resting activities" (item 16) in the Relaxation subscale, is translated as "sleep" in the Italian version. This result suggests that further data must be collected to combine the results of a confirmatory analysis with those of the exploratory analysis.

The Italian version of the TFI shows very high levels of 
internal consistency with Cronbach's alpha: above 0.90 for the overall TFI and for each of the four factors.

The test-retest reliability analysis was carried out on a subgroup of patients and the results showed acceptable to good levels of test-retest reliability $(0.79 \leq \alpha \leq 0.85)$.

In order to assess convergent and discriminant validity, the I-TFI was compared with the original THI, the most widely used tinnitus questionnaire in Italy, which has already been validated in the Italian language and used in other validation studies. The results show a strong positive correlation with the THI, thus confirming that the I-TFI and the THI measure a similar construct.

The I-TFI also shows a high convergent validity with the scores for tinnitus annoyance; this was predictable as the TFI includes aspects related to the annoyance experienced by patients with tinnitus. Instead, the global I-THI score showed marginal correlations compared with the BDI-PC scores, thus indicating acceptable levels of discriminant validity.

There are some limitations in this study. First of all, the number of patients recruited was limited and insufficient to enable us to perform a Confirmatory factor analysis; further studies on a larger number of subjects suffering from tinnitus are needed. Secondly, we did not evaluate the I-TFI responsiveness to treatment-related changes and therefore further research is needed to address this point.

\section{Conclusions}

The difficulties in reproducing the original eight-factor structure are consistent with other TFI validation studies on European language versions of the questionnaire, which also failed to reproduce the original eight-factor structure. In spite of this, the factorial structure of the Italian version of the TFI is characterised by high levels of reliability and validity. Overall, the Italian adaptation of the TFI is suitable for measuring the impact of tinnitus on the daily lives of individuals.

\section{Acknowledgements}

We would like to thank Michele Gunness from Oregon Health \& Science University for providing us the licence of this version.

\section{References}

1 Møller AR, Langguth B, DeRidder D, et al. Textbook of Tinnitus: diagnosis and treatment. New York: Springer; 2010. p.786.

2 Kuk FK, Tyler RS, Russell D, et al. The psychometric properties of a tinnitus handicap questionnaire. Ear Hear 1990;11:434-45. https:// doi.org/10.1097/00003446-199012000-00005

3 Wilson PH, Henry J, Bowen M, et al. Tinnitus reaction questionnaire psychometric properties of a measure of distress associated with Tinnitus. J Speech Hear Res 1991;34:197-201.
4 Newman CW, Jacobson GP, Spitzer JB. Development of the Tinnitus handicap inventory. Arch Otolaryngol Head Neck Surg 1996;122:1438. https://doi.org/10.1001/archotol.1996.01890140029007

5 Goebel G, Hiller W. Tinnitus-Fragebogen (TF). Ein Instrument zur Erfassung von Belastung und Schweregrad bei Tinnitus. Göttingen: Hogrefe; 1998.

6 Hiller W, Goebel G. Rapid assessment of tinnitus-related psychological distress using the Mini-TQ. Int J Audiol 2004;43:600-4. https:// doi.org/10.1080/14992020400050077

7 Tyler R, Ji H, Perreau A, et al. Development and validation of the Tinnitus Primary Function Questionnaire. Am J Audiol 2014;23:260-72. https://doi.org/10.1044/2014_AJA-13-0014

8 Passi S, Ralli G, Capparelli E, et al. The THI questionnaire: psychometric data for reliability and validity of the Italian version. Int Tinnitus J 2008;14:26-33

9 Moschen R, Fioretti A, Eibenstein A, et al. Validation of the Italian Tinnitus Questionnaire Short Form (TQ 12-I) as a brief test for the assessment of Tinnitus-related distress: results of a cross-sectional multicenter-study. Front Psychol 2018;9:65. https://doi.org/10.3389/ fpsyg.2018.00065

10 Moschen R, Fioretti A, Eibenstein A, et al. Validation of the Chronic Tinnitus Acceptance Questionnaire (CTAQ-I): the Italian version. Acta Otorhinolaryngol Ital 2019;39:107-16. https://doi. org/10.14639/0392-100X-2144.

11 Meikle MB, Henry JA, Griest SE, et al. The tinnitus functional index: development of a new clinical measure for chronic, intrusive tinnitus. Ear Hear 2012;33:153-76. https://doi.org/10.1097/ AUD.0b013e31822f67c0

12 Rabau S, Wouters K, Van de Heyning P. Validation and translation of the Dutch tinnitus functional index. B-ENT 2014;10:251-8.

13 Wrzosek M, Szymiec E, Klemens W, et al. Polish translation and validation of the Tinnitus handicap inventory and the Tinnitus Functional Index. Front Psychol 2016;7:1871. https://doi.org/10.3389/fpsyg.2016.01871

14 Hoff M, Kähäri K. A Swedish cross-cultural adaptation and validation of the Tinnitus Functional Index. Int J Audiol 2017;56:277-85. https:// doi.org/10.1080/14992027.2016.1265154

15 Peter N, Kleinjung T, Jeker R, et al. Tinnitus functional index: validation of the German version for Switzerland. Health Qual Life Outcomes 2017;15:94. https://doi.org/10.1186/s12955-017-0669-x

16 Brüggemann P, Szczepek AJ, Kleinjung T, et al. Validation of the German version of Tinnitus Functional Index (TFI). Laryngorhinootologie 2017;96:615-9. https://doi.org/10.1055/s-0042-122342

17 Oron Y, Shemesh S, Tamir SO, et al. A Hebrew adaptation of the tinnitus functional index. Clin Otolaryngol 2018;43:662-5. https://doi. org/10.1111/coa.12985

18 Kam ACS, Leung EKS, Chan PYB, et al. Cross-cultural adaptation and psychometric properties of the Chinese tinnitus functional index. Int J Audiol 2018;57:91-7. https://doi.org/10.1080/14992027.2017.1 375162

19 Kam AC, Leung EK, Chan PY, et al. Cross-cultural adaptation of the Tinnitus Functional Index for measurement of chronic tinnitus in Hong Kong Chinese patients. Hong Kong Med J 2018;24(Suppl 4):42-5.

20 Henry JA, Frederick M, Sell S, et al. Validation of a novel combination hearing aid and tinnitus therapy device. Ear Hear 2015;36:42-52. https://doi.org/10.1097/AUD.0000000000000093

21 Beck AT, Guth D, Steer RA, et al. Screening for major depression disorders in medical inpatients with the Beck Depression Inventory for Primary Care. Behav Res Ther 1997;35:785-91. https://doi. org/10.1016/s0005-7967(97)00025-9

22 Salviati $\mathrm{M}$, Macrì $\mathrm{F}$, Terlizzi $\mathrm{S}$, et al. The tinnitus handicap inven- 
tory as a screening test for psychiatric comorbidity in patients with tinnitus. Psychosomatics 2013;54:248-56. https://doi.org/10.1016/j. psym.2012.05.007

23 Beck AT, Steer RA, Brown GK. Manual for Beck Depression Inventory-II. San Antonio, TX: Psychological Corporation; 1996.

24 Wild D, Grove A, Martin M, et al.; ISPOR Task Force for Translation and Cultural Adaptation. Principles of good practice for the translation and cultural adaptation process for patient-reported outcomes (PRO) measures: report of the ISPOR Task Force for translation and cultural adaptation. Value Health 2005;8:94-104. https://doi. org/10.1111/j.1524-4733.2005.04054.x

25 Kaiser, HF. The application of electronic computers to factor analysis. Educational and Psychological Measurement 1960;20:14151. https://doi.org/10.1177/001316446002000116

26 Fabrigar LR, Wegener DT, Mac Callum RC, et al. Evaluating the use of exploratory factor analysis in psychological research. Psychological Methods 1999;4:272-99.
27 Hinkle DE, Wiersma W, Jurs SG. Applied statistics for the behavioral sciences. Fifth edition. Boston: Houghton Mifflin; 2003.

28 Hutcheson G, Sofroniou N. The multivariate social scientist: introductory statistics using generalized linear models. London: Sage Publication; 1999.

29 Hayton JC, Allen DG, Scarpello V. Factor retention decisions in exploratory factor analysis: a tutorial on parallel analysis. Organizational Research Methods 2004;7:191-205. https://doi. org/10.1177/1094428104263675

30 Green SB. A coefficient alpha for test-retest data. Psychological Methods 2003;8:88-101.

31 Fackrell K, Hall DA, Barry JG, et al. Performance of the Tinnitus Functional Index as a diagnostic instrument in a UK clinical population. Hear Res 2018;358:74-85. https://doi.org/10.1016/j. heares.2017.10.016 